\title{
Assessment of elemental composition and properties of copper smelter-affected dust and its nano- and micron size fractions
}

\author{
Mikhail S. Ermolin $^{1,2} \cdot$ Petr S. Fedotov ${ }^{1,2} \cdot$ Alexandr I. Ivaneev $^{1} \cdot$ Vasily K. Karandashev ${ }^{1,3} \cdot$ Andrey A. Burmistrov $^{2} \cdot$ \\ Yury G. Tatsy ${ }^{2}$
}

Published online: 3 October 2018

(C) Springer-Verlag GmbH Germany, part of Springer Nature 2018

\begin{abstract}
A comprehensive approach has been developed to the assessment of composition and properties of atmospherically deposited dust in the area affected by a copper smelter. The approach is based on the analysis of initial dust samples, dynamic leaching of water soluble fractions in a rotating coiled column (RCC) followed by the determination of recovered elements and characterization of size, morphology and elemental composition of nano-, submicron, and micron par ticles of dust separated using fieldflow fractionation in a RCC. Three separated size fractions of dust $(<0.2,0.2-2$, and $>2 \mu \mathrm{m})$ were characterized by static light scattering and scanning electron microscopy, whereupon the fractions were analyzed by ICP-AES and ICP-MS (after digestion). It has been evaluated that toxic elements, which are characteristics for copper smelter emissions ( $\mathrm{As}, \mathrm{Cu}, \mathrm{Zn}$ ), are accumulated in fraction $>2 \mu \mathrm{m}$. At the same time, up to 2.4, 3.1, 8.2, $6.7 \mathrm{~g} / \mathrm{kg}$ of $\mathrm{As}, \mathrm{Cu}, \mathrm{Zn}, \mathrm{Pb}$, correspondently, were found in nanoparticles $(<0.2 \mu \mathrm{m})$. It has been also shown that some trace elements ( $\mathrm{Sn}, \mathrm{Sb}, \mathrm{Ag}, \mathrm{Bi}$, and $\mathrm{Tl})$ are accumulated in fraction $<0.2$, and their content in this fraction may be one order of magnitude higher than that in the fraction $>2 \mu \mathrm{m}$, or the bulk sample. It may be assumed that $\mathrm{Sn}, \mathrm{Sb}, \mathrm{Ag}, \mathrm{Bi}, \mathrm{Tl}$ compounds are adsorbed onto the finest dust particles as compared to $\mathrm{As}, \mathrm{Cu}, \mathrm{Zn}$ compounds, which are directly emitted from the copper smelter as microparticles.
\end{abstract}

This article was originally intended as an invited contribution to the special issue Bioavailability - The Underlying Basis for Analytical Methods for Characterization of Nano- and Micro-objects but was inadvertently published prematurely in Environmental Science and Pollution Research Volume 23, Issue 23, pp 23781-23790, https://doi.org/10.1007/s11356-0167637-6.

Mikhail S. Ermolin

ermolin@geokhi.ru; mihail.ermolin@gmail.com

1 National University of Science and Technology "MISiS", 4 Leninsky

Prospect, Moscow 119991, Russia

2 Vernadsky Institute of Geochemistry and Analytical Chemistry, Russian Academy of Sciences, 19 Kosygin Street, Moscow 119991, Russia

3 The Institute of Microelectronics Technology and High-Purity Materials, Russian Academy of Sciences, 6 Institution Street, Chernogolovka 142432, Russia 